\title{
Microbiological quality of mink feed raw materials and feed production area
}

\author{
Ulrike Lyhs ${ }^{1,5^{*}}$, Henrik Frandsen², Birgitte Andersen³ ${ }^{3}$ Bettina Nonnemann', Charlotte Hjulsager ${ }^{1,6}$, \\ Karl Pedersen ${ }^{4}$ and Mariann Chriél ${ }^{1,7}$
}

\begin{abstract}
Background: The quality of mink feed and raw ingredients affect health and growth. The objectives of this study were to examine the microbiological quality of ready-to-eat mink feed and its raw ingredients, screen the plant part of the feed for mycotoxins, and determine the hygiene of the production environment in the feed processing facilities. The results of the study are important for identification of critical steps in the feed production and for formulation of recommendations for improvements of production processes to obtain better quality feed. Feed and swab samples were taken at three Danish mink feed producers October 2016 and May 2017, respectively. Viable counts, detection of methicillin-resistant Staphylococcus aureus (MRSA), influenza virus and filamentous fungi were performed together with qualitative chemical analyses for bioactive fungal metabolites and mycotoxins. Swab samples were analyzed for total viable counts.
\end{abstract}

Results: Viable counts varied between $7.2 \times 10^{2}$ and $9.3 \times 10^{7} \mathrm{cfu} / \mathrm{g}$ in raw ingredients and between $10^{7}$ and $10^{9} \mathrm{cfu} /$ $\mathrm{cm}^{2}$ on different surfaces at the feed production facilities. A pork meat product, pork haemoglobin, pork liver and a poultry mix was found positive for MRSA, while monophasic Salmonella [4,5,12:i:-] was detected in a pork meat product. Neither MRSA nor Salmonella was detected in any ready-to-eat feed. Influenza A virus was not detected in any sample. Filamentous fungi were detected in all analysed samples of ready-to-eat feed while dihydro-demethyl-sterigmatocystin was found in almost $50 \%$ of all ready-to-eat feed samples and in $80 \%$ of the sugar beet pulp. Fumonisins and other Fusarium toxins were found especially in corn gluten meal and extruded barley and wheat.

Conclusions: Mink feed contained a cocktail of mycotoxins and bacteria, which may not per se cause clinical disease, but may affect organ function and animal performance and well-being.

Keywords: Aspergillus, Clostridium, Hygiene, Influenza A virus, Mink, Mycotoxins

\section{Background}

Denmark is the world's largest producer of mink skins. The American mink (Neovison vison) is used for livestock production with 1248 commercial mink farms registered in 2018, which produced approximately 17.2 million mink skins (https://statistikbanken.dk). Feed factories supply the mink farms with pumpable wet feed consisting of a mix of animal by-products and slaughter offal (e.g. by-product from the fishing and meat industries)

\footnotetext{
*Correspondence: ulrike.lyhs@helsinki.fi

${ }^{5}$ Present Address: Institute for Molecular Medicine Finland (FIMM), University of Helsinki, P.O.Box 20, Tukholmankatu 8, 00014 Helsinki, Finland

Full list of author information is available at the end of the article
}

and plant origin (e.g. corn gluten meal, soybean oil and extruded cereals).

Raw ingredients of animal origin, mainly fish and poultry products and their by-products, are susceptible to bacterial contamination and spoilage. Likewise, ingredients of plant origin are susceptible to fungal spoilage and synthesis of mycotoxins. Spoilage microorganisms will always impair the quality, digestibility and the nutritional value of the feed and consequently, reduce not only the productivity of the animals, but also their health, behaviour and welfare. Limited work has been carried out to investigate the microbiological quality of mink feed. When analysing bacterial counts including enterococci, coliforms, haemolytic and sulphite-reducing bacteria 
in different raw materials, Juokslahti [1] reported high bacterial counts in fish by-product and blood meal with slaughterhouse by-product and unpreserved slaughter blood having the poorest quality.

The ready-to-eat feed may contain pathogenic or toxigenic bacteria, fungi and viruses originating from contaminated raw materials, which may cause diseases in the mink. Dietz et al. [2] described Salmonella Dublinassociated abortion in Danish mink and fox farms concluding that contaminated feed was responsible for the outbreaks. Other studies described uterine infections of mink caused by Clostridium limosum with suspicion of feed-borne transmission [3]. Hammer et al. [4] reported a spontaneous outbreak of abortions and mortality in Danish mink farms probably due to C. limosum found in raw mink feed samples. Hansen et al. [5] found livestockassociated methicillin-resistant Staphylococcus aureus (LA-MRSA) in 20 out of 58 (34\%) of clinical mink samples and in 20/108 (19\%) of feed samples. Studies have shown mink to be sensitive to a number of mycotoxins, including aflatoxin B1, deoxynivalenol, zearalenone, fumonisins, moniliformin and ergot alkaloids [6]. Bursian et al. [6] also showed that mink lost weight and developed kidney damage when fed ochratoxin contaminated feed. Aflatoxin-containing feed can cause poor skin quality, weight loss and kidney and liver damage [7], while deoxynivalenol (DON, vomitoxin) and other Type B trichothecenes have been demonstrated to cause emesis in the mink [8].

Analyses of medication and feed quality showed that the consumption of antibiotics increased when the numbers of faecal cocci were high $[9,10]$ although a direct association needs to be further verified. Poor feed quality may therefore indirectly lead to increased antimicrobial use. An earlier study of gastrointestinal disorders in mink found that differences between the feed producers as a risk factor accounted for $80 \%$ of the variation in occurrence of gastrointestinal disorders [11]. Antibiotics are often used for treating unspecific diarrhoea or clinical pneumonia, and to a lesser extent in sporadic outbreaks of contagious diseases, such as Pseudomonas aeruginosa, and secondary infections after outbreak of mink influenza or canine distemper. However, resistance in the bacterial population is amplified by selection pressure from antibiotics use, which may result in reduced or-in worst case-no effect of the antibiotic treatment $[12,13]$.

Good quality of feed is essential for the animal performance, health and welfare. This applies to both nutritional value and microbiological quality. In the present study, we have focussed on the bacterial and mycological quality with the purposes to: (1) examine the microbiological quality of the raw ingredients (animal and plant origin) and the ready-to-eat mink feed; (2) screen the plant ingredients and ready-to-eat feed for mycotoxins and; (3) determine the hygiene level of the production environment in the feed processing facilities. The results may be important to identify any critical steps in the production of feed and may therefore be important to assist the feed factories in improving production processes to obtain better quality feed.

\section{Methods}

\section{Collection and transport of the samples}

Three Danish mink feed producers (coded A to C) were visited twice: when the feed production was at its maximum volume (late October 2016) and at its minimum (mid May 2017). From each producer, 20 samples from each raw ingredient of animal origin, five samples from each raw ingredient of plant origin and five samples from the final product (ready-to-eat feed) were collected on each visit. For each frozen sample type, the feed producer used a machine to drill a hole in the frozen pallets of feed ingredients. The cylinder of feed ingredient left on the drill was transferred to a sample container. Between each sample collection, the drill was rinsed with hot water $\left(>50{ }^{\circ} \mathrm{C}\right)$. For the all other sample types, samples were taken randomly from the feed ingredients and transferred to a sample container. They were placed in a cool box and transported immediately to the laboratory and subjected to bacterial analyses within 4 to $6 \mathrm{~h}$. The number of sample types collected from all three mink feed producers during both sampling years and the number of analyses performed on them are indicated in Table 1.

In each sampling year, a total of 25 swab samples were taken from five different surfaces $(10 \times 10 \mathrm{~cm})$ at all three feed producers. For transport to the laboratory, five swabs from the same surface were pooled to one subsample and placed into a sterile tube containing $10 \mathrm{~mL}$ of $0.9 \% \mathrm{NaCl}(\mathrm{w} / \mathrm{v})$ and $0.1 \%(\mathrm{w} / \mathrm{v})$ peptone water and stored at $4{ }^{\circ} \mathrm{C}$.

\section{Microbiological analyses Detection of bacteria in samples of animal origin}

Twenty-five gram of each raw feed ingredient of animal origin and of the ready-to-eat feed product (one pooled sample of five subsamples of $5 \mathrm{~g}$ each), respectively, were aseptically transferred to a Stomacher ${ }^{\circledR} 400$ bag (Seward BA6041, Worthing, UK) containing $225 \mathrm{~mL}$ of $0.9 \% \mathrm{NaCl}$ $(\mathrm{w} / \mathrm{v})$ and $0.1 \%(\mathrm{w} / \mathrm{v})$ peptone water. The bag was blended in a Stomacher 400 Lab Blender (Seward Medical, London, UK) for $3 \mathrm{~min}$. Tenfold serial dilutions were used for microbiological analyses. Total viable counts (TVC) were performed on spread plates with Plate Count Agar (PCA) (Thermo Fisher Scientific, Roskilde, Denmark) according to method ISO 4833-2:2012 [14]. The number of Enterobacteriaceae was determined by pour plating 
Table 1 Type of sample, analyses and total number of samples taken from three mink feed producers during October 2016 and May 2017

\begin{tabular}{ll}
\hline Samples & Type of analyses \\
\hline Raw ingredients of animal origin & Detection of bacteria \\
& Detection of influenza A virus \\
of samples & Detection of fungal metabolites and mycotoxins \\
Raw ingredients of plant origin & Detection of fungal metabolites and mycotoxins \\
Ready-to-eat feed I & Detection of bacteria \\
& Detection of influenza A virus \\
& Detection of filamentous fungi \\
& Detection of fungal metabolites and mycotoxins \\
& Detection of bacteria
\end{tabular}

in Violet Red Bile Glucose (VRBG) agar (Oxoid, Basingstoke, UK) according to the method of ISO 21528-2:2004 [15]. Counts of clostridia were done by pour plating method on Tryptose Sulfite Cycloserine (TSC) agar (Oxoid) by the method ISO 7937:2004 (E) [16]. Escherichia coli counts were determined on spread MacConkey agar plates (Thermo Fisher Scientific) using ISO 166492:2001 [17], except that we used MacConkey agar instead of 5-bromo-4-chloro-3-indolyl beta-D-glucuronide. The number of staphylococci were performed on spread plates with Baird-Parker agar (Thermo Fisher Scientific) according to the method of ISO 6888-1:1999 [18]. All PCA plates were counted after 3 days' aerobic incubation at $30{ }^{\circ} \mathrm{C}$. Typical Enterobacteriaceae colonies were counted after $18-24 \mathrm{~h}$ aerobic incubation at $37{ }^{\circ} \mathrm{C}$. Both MacConkey and Baird-Parker plates were counted after 18-24 h and 2 days, respectively, aerobic incubation at $37^{\circ} \mathrm{C}$. TSC plates were counted after $18-24$ h anaerobic incubation at $37^{\circ} \mathrm{C}$.

From each ready-to-eat feed product, one subsample (ready-to-eat feed I) was immediately analyzed for bacteria as described before $(t=0)$. In order to simulate handling of the final feed product before mink may eat the feed, a second subsample (ready-to-eat feed II) was stored in the sampling container with lid open in room temperature overnight and analyzed the next day $(\mathrm{t}=24)$.

For comparison of viable counts between seasons and feed factories, viable counts were log-transformed and hereafter compared using two-sided t-test.

For detection of Salmonella spp. [19], 25 g each of raw feed ingredient of animal origin and ready-to-eat feed $(t=0$ and $t=24)$, respectively, were aseptically transferred into a Stomacher ${ }^{\circledR} 400$ bag (Seward BA6041) containing $225 \mathrm{~mL}$ of buffered peptone water (BPW) (Thermo Fisher Scientific), then blended in a Stomacher 400 Lab Blender (Seward Medical) for 3 min and incubated at $37{ }^{\circ} \mathrm{C}$ for $16-20 \mathrm{~h}$. Three drops (totaling
$0.1 \mathrm{~mL}$ ) of this BPW pre-enrichment culture were equally inoculated on Modified Semisolid Rappaport-Vassiliadis (MSRV) agar (Thermo Fisher Scientific) plates and incubated at $41.5^{\circ} \mathrm{C}$ for $18-24 \mathrm{~h}$. From MSRV, suspect growth was sub-cultivated on Brilliant Green Agar (BGA) (Thermo Fisher Scientific) and on Xylose Lysine Deoxycholate (XLD) Agar (Thermo Fisher Scientific). Similar to transferring BPW to MSRV plates, $1 \mathrm{~mL}$ of BPW was transferred into $9 \mathrm{~mL}$ Selenite Cystine (SC) broth (Thermo Fisher Scientific) and incubated for $18-24 \mathrm{~h}$ at $41.5^{\circ} \mathrm{C}$. From here, the BGA and XLD agar were inoculated. Suspect colonies from XLD and BGA were subcultured on Columbia agar plates containing 5\% calf blood (SSI Diagnostica, Hillerød, Denmark) and verified by agglutination with polyvalent Salmonella serum (SSI Diagnostica).

\section{Detection of methicillin-resistant Staphylococcus aureus (MRSA)}

For detection of MRSA, raw feed ingredients of animal origin and of the ready-to-eat feed product were kept frozen until analysis. All samples were analysed by one-step enrichment, where $10 \mathrm{~g}$ were inoculated in $90 \mathrm{~mL}$ Mueller-Hinton Broth with $6.5 \% \mathrm{NaCl}$ for $18-24 \mathrm{~h}$ at $37{ }^{\circ} \mathrm{C}$ without agitation. A loop-full $(10 \mu \mathrm{L})$ enriched sample material was streaked on Brilliance MRSA2 agar (Oxoid) and incubated at $37^{\circ} \mathrm{C}$ for $18-24 \mathrm{~h}$. Presumptive MRSA colonies identified as denim blue colonies on MRSA2 agar were sub-cultured on agar plates (Oxoid) containing $5 \%$ calf blood for further verification. Isolates were identified as MRSA by PCR detection of the mecA and nuc genes [20].

Detection of filamentous fungi in ready-to-eat feed samples For determination of filamentous fungi present in the feed, $1 \mathrm{~g}$ of thawed, ready-to-eat feed product was transferred directly to Dichloran 18\% Glycerol agar (DG18 
([21])) and spread over the surface of the agar. Likewise, $1 \mathrm{~g}$ from each ready-to-eat product was plated onto vegetable juice agar (V8 ([21])). The plates were incubated in darkness at $20^{\circ} \mathrm{C}$ and read after 5,7 and 10 days. Representative fungi were isolated and inoculated onto different media for species identification according to Samson et al. [21]. In brief: Aspergillus cultures were 3-point inoculated onto CYA, MEA and DG18 and incubated in darkness at $25{ }^{\circ} \mathrm{C}$ and CYA at $37{ }^{\circ} \mathrm{C}$. Penicillium cultures were 3-point inoculated onto CYA, MEA and YES and incubated in darkness at $25{ }^{\circ} \mathrm{C}$ and CYA at $30{ }^{\circ} \mathrm{C}$. Zygomycetes were 1-point inoculated on MEA, OA and DG18 [21] and incubated in darkness at $25^{\circ} \mathrm{C}$ and MEA at $30{ }^{\circ} \mathrm{C}$.

\section{Detection of bacteria in environmental samples}

In the laboratory, $90 \mathrm{~mL}$ of $0.9 \% \mathrm{NaCl}(\mathrm{w} / \mathrm{v})$ and $0.1 \%$ $(\mathrm{w} / \mathrm{v})$ peptone water were added to each tube containing five pooled swabs and vortexed for $30 \mathrm{~s}$. Tenfold serial dilutions were used for microbiological analyses. Total viable counts (TVC) were performed on spread plates with Plate Count Agar (PCA) (Thermo Fisher Scientific) as described above.

\section{Detection of influenza virus $A$}

RNA was purified from all raw feed ingredients of animal origin (except blood meal and pork fat) and from readyto-eat feed. Liquid samples were pre-treated by lysing $200 \mu \mathrm{L}$ of sample in $400 \mu \mathrm{L}$ of RLT Buffer (QIAGEN) with $1 \% \beta$-mercaptoethanol while solid samples were homogenized by beating on a Tissue lyser II (QIAGEN) to prepare $10 \%$ homogenate in RLT Buffer (QIAGEN) with $1 \% \beta$-mercaptoethanol. RNA was purified from $600 \mu \mathrm{L}$ homogenate/lysate using RNeasy Mini Kit (QIAGEN) on a QIAcube (QIAGEN) purification robot with protocol animal tissues and cells, large samples, version 2. The RNA was tested for influenza A virus using realtime RT-PCR directed against the matrix gene [22]. In order to counteract possible PCR inhibition, the test was performed on both undiluted RNA and on RNA diluted tenfold in nuclease-free water.

\section{Chemical analyses}

\section{Detection of mycotoxins and other bioactive fungal} metabolites

Acetonitrile, methanol, formic acid and 25\% ammonium hydroxide (LC-MS grade) and ethyl acetate were obtained from Sigma-Aldrich, Schnelldorf, Germany. Evolute express ABN SPE columns were obtained from Biotage, Sweden. Water was purified on a Milli Q system (Millipore Corporation, USA). Aflatoxin B1, B2, G1, and G2, citrinin, cyclopiazonic acid, deoxynivalenol, enniatin
$\mathrm{A} 1$ and B1, fumonisin B1 and B2, nivalenol, ochratoxin A, patulin, sterigmatocystin, T2 toxin and zearalenone were all obtained from Sigma-Aldrich.

\section{Sample preparation}

Sample material of $0.2 \mathrm{~g}$ (ready-to-eat feed or raw material) was transferred to a bead beater tube and added $1 \mathrm{~mL} \mathrm{80 \%} \mathrm{acetonitrile.} \mathrm{After} \mathrm{homogenization} \mathrm{for} 1 \mathrm{~min}$ the tube was cooled to $4{ }^{\circ} \mathrm{C}$ and centrifuged at $10,000 \times g$. The supernatant was transferred to an Eppendorf tube and frozen at $-20{ }^{\circ} \mathrm{C}$ for $1 \mathrm{~h}$ followed by centrifugation at $10,000 \times g$ at $4{ }^{\circ} \mathrm{C}$ for $10 \mathrm{~min}$. A SPE column (evolute express $A B N 30 \mathrm{mg}$ ) was washed with $2 \mathrm{~mL}$ acetonitrile and dried and $0.3 \mathrm{~mL}$ of the supernatant was passed through the column and transferred to a HPLC vial.

\section{Liquid chromatography quadrupole time-of-flight mass spectrometry}

Liquid chromatography was performed on a Dionex Ultimate 3000 RS (Thermo Scientific) with a Poroshell SB C-18 column (100 mm length and $2.1 \mathrm{~mm}$ inner diam., $2.7 \mu \mathrm{m}$ particle size) column held at $30{ }^{\circ} \mathrm{C}$ (Agilent Technologies, Walbron, Germany). The solvent system consisted of A: $2.5 \mathrm{mM}$ ammonium hydroxide $+0.02 \%$ formic acid in water and B: methanol. Solvent programming were: $10 \% \mathrm{~B}$ at 0 min followed by a linear gradient to $45 \% \mathrm{~B}$ at $3 \mathrm{~min}$ and a linear gradient to $95 \% \mathrm{~B}$ at $14 \mathrm{~min}$, isocratic $95 \% \mathrm{~B}$ from 14 to $16 \mathrm{~min}$ followed by reversal to initial conditions at $16.1 \mathrm{~min}$ and re-equilibration of the column to $20 \mathrm{~min}$. The flow rate was $0.2 \mathrm{~mL} /$ min from 0 to $1 \mathrm{~min}$ followed by a linear gradient to $0.4 \mathrm{~mL} / \mathrm{min}$ to $14 \mathrm{~min}$, which was held until $16 \mathrm{~min}$ followed by reversal to initial conditions at $19 \mathrm{~min}$.

The LC system was connected to a Bruker Daltonics, maXis qTOF mass spectrometer equipped with an electrospray ion source operated in positive ion mode (Bruker Daltonics, Bremen, Germany). The ion source settings were: nebulizer pressure 2 bars, drying gas flow $8 \mathrm{~L} / \mathrm{min}$, dry gas temperature $200^{\circ} \mathrm{C}$, and capillary voltage $4000 \mathrm{~V}$. The scan range was from 30 to $1000 \mathrm{~m} / \mathrm{z}$ with an acquisition rate of $2 \mathrm{~Hz}$. Sodium formate dissolved in 50\% 2-propanol was introduced in the ion source in a 0.2-0.4 min time segment and used for internal calibration of the data files. Hexakisperflouroethoxyphophazene was used as lock mass calibrant (Apollo Scientific, UK).

\section{Fungal metabolite analyses}

Data files were processed using Target Analysis (Bruker Daltonics). Based on information on the elemental composition of the analytes the software extracts ion chromatograms of the exact mass $\pm 3 \mathrm{mDa}$ of aflatoxin B1, B2, G1, and G2, citrinin, cyclopiazonic acid, deoxynivalenol, enniatin A1 and B1 (ammonium adducts), fumonisin B1 
and B2, nivalenol, ochratoxin A, patulin, sterigmatocystin, T2 toxin and zearalenone followed by integration of the chromatograms and reporting of the results.

\section{pH-measurement}

The $\mathrm{pH}$ was determined from the first homogenate made for microbiological analysis by a Sartorius PB 310 Digital-pH-meter, Type PHM 92, (Radiometer, Analytical A/S, Copenhagen, Denmark).

\section{Results}

\section{Bacteriological analyses}

The bacterial counts for each raw ingredient of animal origin and the ready-to-eat feed I and II from all three feed producers (A to C) in both sampling years 2016 and 2017 are shown in Additional files 1, 2, 3, 4, 5 and 6. Note that there are differences in sample categories between the years for the same producer.

In the raw ingredients from feed producer $\mathrm{A}$ in both sampling years 2016 and 2017, total viable count (TVC) between $1.8 \times 10^{4}$ and $9.3 \times 10^{7}$ colony-forming units/g $(\mathrm{cfu} / \mathrm{g})$ were found in most of the raw ingredients except in the fish silage (Additional files 1 and 4). In 2016, high Enterobacteriaceae counts were determined in raw ingredients from fish and pork products, but only low counts from poultry by-products $\left(2.6 \times 10^{7} \mathrm{cfu} / \mathrm{g}\right)$ in 2017 . In 2017, samples from poultry by-products and fish cut showed E. coli counts of $4.7 \times 10^{7}$ and $9.4 \times 10^{5} \mathrm{cfu} / \mathrm{g}$, respectively (Additional file 4 ). In the same year, counts of staphylococci up to $2.4 \times 10^{6} \mathrm{cfu} / \mathrm{g}$ were detected in poultry by-products.

In 2016, TVC of all ingredients from feed producer $B$ varied between $7.2 \times 10^{2}$ and $9.2 \times 10^{4} \mathrm{cfu} / \mathrm{g}$ (Additional file 2). In 2017, TVC of $1.3 \times 10^{4}$ and $5.4 \times 10^{4} \mathrm{cfu} / \mathrm{g}$ were found in fish cut and industrial fish, respectively (Additional file 5: Table S5).

In 2016, in all ingredients from feed producer C, TVC were between $2.6 \times 10^{3}$ and $3.8 \times 10^{4} \mathrm{cfu} / \mathrm{g}$. In the same year, clostridial counts of $1.9 \times 10^{4} \mathrm{cfu} / \mathrm{g}$ were found in fish cut and of $4 \times 10^{4} \mathrm{cfu} / \mathrm{g}$ in poultry by-product (Additional file 3). In 2017, in blood samples all bacterial counts except clostridia were between $2.1 \times 10^{3}$ and $4.4 \times 10^{5} \mathrm{cfu} / \mathrm{g}$ (Additional file 6).

In both sampling years in all three feed producers, TVC of the ready-to-eat feed I varied between $9.8 \times 10^{4}$ and $1.1 \times 10^{7} \mathrm{cfu} / \mathrm{g}$ (Additional files 1, 2, 3, 4, 5 and 6). After storage overnight, TVC for the ready-to-eat feed II increased for all three producers to counts between $4.2 \times 10^{7}$ and $1.4 \times 10^{9} \mathrm{cfu} / \mathrm{g}$.

In 2016, environmental samples from different surfaces, e.g. from the conveyor belts for the ingredients and for the final products, the mixer, the ready-to-eat feed silo, the distribution auger and the homogenizer showed
TVC between $10^{7}$ and $10^{9} \mathrm{cfu} / \mathrm{cm}^{2}$ (Table 2) in all three feed producers. In 2017, lower TVC were detected from the environmental samples in all three feed producers (Table 2).

The TVC were not statistically significantly different between seasons (autumn 2016 versus spring 2017) $(P>0.05)$. However, there was significant difference between feed factories, i.e. factory A had significantly higher counts than factory $B$ and $C$, whereas there was no difference between $B$ and $C$.

In 2016, pork meat product from feed producer A and in 2017, both haemoglobin and pork liver from feed producer A and poultry mix from feed producer B were positive for MRSA. In 2017, Salmonella Typhimurium

Table 2 Total viable counts of bacteria $\left(\mathrm{cfu} / \mathrm{cm}^{2}\right)$ from swab samples taken from the production facility at three feed producers (A-C) in 2016 and 2017

\begin{tabular}{|c|c|c|}
\hline $\begin{array}{l}\text { Feed producer } \\
\text { (year) }\end{array}$ & Sampling location & $\begin{array}{l}\text { Total viable } \\
\text { bacteria (cfu) } \\
\mathrm{cm}^{2} \text { ) }\end{array}$ \\
\hline \multirow[t]{5}{*}{ A (2016) } & Mixer 629 & $5.5 \times 10^{5}$ \\
\hline & Auger 626 & $4.6 \times 10^{4}$ \\
\hline & Conveyor belt 620 & $4.6 \times 10^{8}$ \\
\hline & Conveyor belt 810 & $1.5 \times 10^{5}$ \\
\hline & Final product silo & $1.7 \times 10^{9}$ \\
\hline \multirow[t]{5}{*}{ A (2017) } & Final product silo & $1.5 \times 10^{3}$ \\
\hline & Conveyor belt to homogenizer & $4.5 \times 10^{2}$ \\
\hline & Floor in room 1 & $2.7 \times 10^{6}$ \\
\hline & Mincer & $<100$ \\
\hline & Chain conveyer & $<100$ \\
\hline \multirow[t]{5}{*}{ B (2016) } & Homogenizer & $5.0 \times 10^{8}$ \\
\hline & Conveyor belt to chopper & $3.5 \times 10^{7}$ \\
\hline & Mixer 1 & $1.5 \times 10^{9}$ \\
\hline & Distribution auger & $1.8 \times 10^{9}$ \\
\hline & Conveyor belt to silo & $1.2 \times 10^{5}$ \\
\hline \multirow[t]{5}{*}{ B (2017) } & Final product silo 701 & $9.0 \times 10^{2}$ \\
\hline & Final product silo 711 & $2.8 \times 10^{4}$ \\
\hline & Conveyor belt 810 & $1.9 \times 10^{4}$ \\
\hline & Conveyor belt 620 & $6.0 \times 10^{4}$ \\
\hline & Distribution auger 626 & $5.0 \times 10^{2}$ \\
\hline \multirow[t]{5}{*}{ C (2016) } & Auger 391 & $1.3 \times 10^{3}$ \\
\hline & Auger 412 & $2.3 \times 10^{3}$ \\
\hline & Auger 410 & $<100$ \\
\hline & Auger 436 & $4.0 \times 10^{7}$ \\
\hline & Mixer 421 & $6.0 \times 10^{2}$ \\
\hline \multirow[t]{5}{*}{ C (2017) } & Auger 410 & $2.9 \times 10^{3}$ \\
\hline & Auger 391 & $1.0 \times 10^{2}$ \\
\hline & Conveyor belt & $1.8 \times 10^{5}$ \\
\hline & Auger 412 & $2.0 \times 10^{2}$ \\
\hline & Auger 422 & $7.2 \times 10^{2}$ \\
\hline
\end{tabular}


monophasic variant [4,5,12:i:-] was detected in a pork meat product from feed producer A. Neither MRSA nor Salmonella were detected in the ready-to-eat feed from any of the three feed producers. All samples of raw ingredients and ready-to-eat feed were influenza-negative.

\section{Fungal and mycotoxin analyses}

Fungal analyses were made on 10 ready-to-eat feed samples from 2016. All samples contained Zygomycetes (Absidia corymbifera, Mucor racemosus, Rhizopus oryzae, R. stolonifer and/or Syncephalastrum racemosum), while three of the samples also contained Aspergillus niger, A. flavus and/or A. glaucus. In nine samples Penicillium discolor was detected whereas P. polonicum was detected in five and P. albocoremium in one sample (Table 3). The qualitative chemical analyses for mycotoxins showed a compound with the same molecular mass as aflatoxin B1 $\left[(\mathrm{M}+\mathrm{H})^{+} 313.0707\right.$ Dalton $\left./ \mathrm{Rt}=7.4 \mathrm{~min}\right]$ in all samples, but different retention time $\mathrm{Rt}=7.9 \mathrm{~min}$. One structure dihydro-demethyl-sterigmatocystin $\left[(\mathrm{M}+\mathrm{H})^{+} 313.0707\right.$ Dalton] a precursor to aflatoxins, fits the data. Furthermore, enniatins were found in six samples and one sample also contained deoxynivalenol (DON) (Additional file 7).

Fifty-six samples of raw ingredients and ready-to-eat feed were screened for the presence of mycotoxins and other bioactive fungal metabolites. The results (Table 4) showed large variation in occurrence as well as in

Table 3 Microbiological quality/fungal species present in samples of ready-to-eat feed from the three feed producers (A to C)

\begin{tabular}{llll}
\hline Producer & Aspergillus species & Penicillium species & $\begin{array}{c}\text { Absidia, Mucor, Rhizopus } \\
\text { and Syncephalastrum } \\
\text { species }\end{array}$ \\
\hline A & A. niger, A. glaucus & P. discolor & Ab. corymbifera \\
B & - & P. discolor, P. polonicum & M. racemosus \\
B & - & P. albocoremium & M. racemosus \\
B & - & P. discolor, P. polonicum & M. racemosus, R. stolonifer \\
B & - & P. discolor & R. stolonifer \\
B & - & P. discolor, P. polonicum & M. racemosus, R. oryzae \\
B & A. flavus, A. glaucus & P. discolor, P.polonicum & S. racemosum \\
B & A. niger, A. glaucus & P. roqueforti & Ab. corymbifera, M. racemosus \\
B & A. flavus, A. niger & P. discolor, P. polonicum & S. racemosum \\
C & A. flavus, A. niger & P. discolor & Ab. corymbifera \\
\hline
\end{tabular}

Table 4 Qualitative determination of mycotoxins and other biologically active metabolites present in samples of the different ingredients and ready-to-eat feed samples from the three feed producers (A to C)

\begin{tabular}{llllll}
\hline Sample type (number of samples) & Aflatoxins & DHDMST $^{\mathbf{a}}$ & Fumonisins & Enniatins & $\begin{array}{l}\text { Other fungal mycotoxins/metabolites } \\
\text { (number of samples) }\end{array}$ \\
\hline Arbocel $(n=3)$ & 0 & 1 & 1 & 1 & 0 \\
Bio fiber $(n=1)$ & 0 & 1 & 0 & 1 & Zearalenone (1) \\
Corn gluten meal $(n=5)$ & 0 & 1 & 3 & 0 & Deoxynivalenol (2), Nivalenol (2), Zearalenone (3) \\
Extruded barley $(n=8)$ & 0 & 1 & 2 & 4 & Deoxynivalenol (1) \\
Extruded wheat $(n=4)$ & 0 & 0 & 0 & 2 & Deoxynivalenol (1), zearalenone (1) \\
Plant silage $(n=2)$ & 0 & 0 & 1 & 0 & Deoxynivalenol (1) \\
Soybean meal $(n=3)$ & 0 & 0 & 0 & 2 & Zearalenone (1) \\
Soybean oil $(n=4)$ & 0 & 0 & 0 & 0 & 0 \\
Sugar beet pulp $(n=5)$ & 0 & 4 & 1 & 4 & 0 \\
Blood meal $(n=2)$ & 0 & 0 & 0 & 0 & 0 \\
Haemoglobin $(n=1)$ & 0 & 0 & 0 & 0 & 0 \\
Meat product $(n=1)$ & 0 & 0 & 0 & 0 & 0 \\
Pigs fat $(n=2)$ & 0 & 0 & 0 & 0 & 0 \\
Ready-to-eat feed $(n=15)$ & 0 & 3 & 0 & 2 & 0 \\
\hline
\end{tabular}

a Dihydro-demethyl-sterigmatocystin 
concentrations of mycotoxins depending on the type of the raw materials. No fungal metabolites were detected in the ingredients of animal origin (e.g. blood meal or pig fat). Aflatoxins, citrinin, cyclopiazonic acid, patulin or ochratoxin were not detected in any of the ingredients of plant origin, however, high concentrations of dihydrodemethyl-sterigmatocystin (DHDMST, a precursor for aflatoxin) were detected in several ingredients of plant origin (e.g. sugar beet pulp and bio fibres). Fusarium metabolites were found in most of the ingredients of plant origin (Table 4). Fumonisins were detected in 7 out of the 31 plant-based ingredients, deoxynivalenol in 5 and zearalenone in six samples, whereas enniatins were detected in 12 of the 31 samples. Several ingredients and ready-to-eat feed samples contained more than one fungal metabolite or mycotoxin. No metabolites from Zygomycetes or Penicillium were found in the samples.

\section{Discussion}

The microbiological quality of feed is as important as the composition to ensure optimal growth and health of production animals. This study has shown that in both sampling years there is a great variety in bacterial counts between both similar and different types of raw ingredients and the three producers. Due to a continuous slaughter, by-products from slaughterhouses and the use of highly perishable raw ingredients like fish or poultry, these ingredients need preservation in order to maintain good microbiological quality when the feed is offered to the mink. Different treatments, like freezing (fish), heat treatment up to $90{ }^{\circ} \mathrm{C}$ (poultry) or acid treatment (silage of fish or spent laying hens) are used. However, high total viable counts (TVC) of bacteria up to $10^{7} \mathrm{cfu} / \mathrm{g}$ were found in both fish and poultry ingredients. Juokslahti [1] reported high bacterial counts in fish by-product and unpreserved slaughter blood in a study from 1979. Although both cooling and hygiene for by-products may have improved since then, we still found high or moderate high bacterial counts in fish products and in haemoglobin and other blood products from pigs. The high moisture and nutrient content of fish and poultry-based ingredients are favoring the growth of microorganisms [23]. Elevated temperature during transport and storage are likely the cause of the high bacterial counts of some ingredients seen in the present study. It is noteworthy that there were differences in viable counts between feed factories. It is not known whether this was due to differences in the quality of the raw materials the factories received or differences in procedures, such as treatment, transport or storage of raw materials and final products. Notwithstanding, the observation suggests that there is potential to improve the microbiological quality of the feed. This may be obtained by preventing growth of microorganisms or reducing their numbers e.g. using acidification or heat treatment, while others have suggested a beneficial effect of lactic acid fermentation [24].

To the authors' knowledge, few studies have been published on the bacterial counts of freshly produced readyto-eat mink feed products. When studying the effect of mink feed supplementation with sodium bentonite, Wlazlo et al. [25] reported TVC of $1.5-2.7 \times 10^{6} \mathrm{cfu} / \mathrm{g}$ in ready-to-eat products. During this study, TVC between $10^{4}$ and $10^{7} \mathrm{cfu} / \mathrm{g}$ were found in the ready-to-eat feed. When we simulated time/temperature procedures (corresponding to normal feeding of farm mink) of the ready-to-eat feed by storing sampling containers with lid open at room temperature overnight, TVC increased up to $1.4 \times 10^{9} \mathrm{cfu} / \mathrm{g}$ in ready-to-eat feed II. This result more or less corresponds to the bacterial concentration in a fully outgrown broth culture, and clearly shows the importance of maintaining the correct temperature of the ready-to-eat feed product during storage in the feed production facilities. Furthermore, bacteria can spread to the raw ingredients and ready-to-eat feed product during contact with contaminated feed handling equipment and storage containers. This condition applies not only to the feed producer, but also to mink farms, where cleaning and disinfection of feed silos and feeders should be included in daily routines. High bacterial counts of the environmental samples swapped from different surfaces at the feed production facilities with levels of $10^{7}$ to $10^{9} \mathrm{cfu} / \mathrm{cm}^{2}$ for TVC indicate low hygiene, poor cleaning and manufacturing practices. Thus, there is a risk of recontamination of raw ingredients and final ready-toeat product by feed- and processing handling equipment and during storage. Several mink diseases caused by e.g. Enterobacteriaceae, E. coli, staphylococci and streptococci are caused by contaminated or spoiled feed [26].

Influenza A virus was not detected in the feed studied, but outbreaks of influenza in mink have previously been linked to feed as a potential source of infection [27]. Gagnon et al. [28] isolated H3N2 influenza A virus from Canadian mink and speculated uncooked pork meat byproducts obtained from slaughterhouse facilities to be the source of transmission. As far as known, influenza viruses have never been detected directly in feed. However, it may be quite difficult to detect influenza viruses in feed as viruses do not multiply in the feed the way that bacteria do, and since only a very small proportion of each feed portion was tested.

In the present study, LA-MRSA was only found in raw ingredients: pork meat product, pork haemoglobin, pork lever and poultry mix. All samples of readyto-eat feed were LA-MRSA negative. Hansen et al. [5] reported LA-MRSA in 20/108 (19\%) of final mink feed products. LA-MRSA was also widely found on the paws 
and in the pharynx of the mink, and spill-over from pig production via raw slaughter by-product was strongly suggested to be the source [29]. In our case, all pork by-products were frozen and the poultry mix was heat treated when mixed into the final product. Salmonella Typhimurium was detected in a pork meat product, but not in the final products. Dietz et al. [2] concluded Salmonella Dublin-contaminated feed to be associated with an abortion storm in Danish mink and fox farms. Salmonella infections are zoonotic, which can lead to infections in both humans and animals. Our findings of pathogenic bacteria show that proper treatment and processing of raw ingredients are essential to reduce the risk of both the contamination of the ready-to-eat feed and a possible exposure to humans during handling the feed.

The results of the mycological analyses show that the ready-to-eat feed products were heavily contaminated with different fungal species, especially Zygomycetes, Penicillium and Aspergillus spp. Our results correspond well with a study on poultry feed, where Penicillium was the most frequent genus, followed by Aspergillus and Mucor [30].

Zygomycetes are fast growing, soil fungi [31] that produce up to $2 \mathrm{~cm}$ high hairy surface mycelium within days [32]. Food- and feed-borne Zygomycetes are not known to produce mycotoxins or other bioactive fungal metabolites [32,33]. However, their presence is suggestive of a poor hygiene in the production facility. Penicillium discolor was the most dominant species in the ready-to-eat feed products followed by $P$. polonicum. They both tolerate low temperatures, low $\mathrm{pH}$ values and low water activities [21] and are commonly found on nuts and cereals in temperate climates $[21,32]$. Their presence suggests contamination of stored, processed cereals (e.g. barley or wheat). Aspergillus flavus together with $A$. niger and A. glaucus were found in samples collected in August and November 2016. These fungi thrive at higher temperatures and lower water activities than the Penicillium species and are common on stored cereals, and on nuts, beans and cereals grown in the tropics or subtropics [21, 32]. Aspergillus flavus and A. niger are known mycotoxin producers [21], but only dihydro-demethyl-sterigmatocystin and Fusarium mycotoxins were detected in this study. Their presence suggests contamination in the field and/or during storage of cereals (e.g. maize). A number of Fusarium toxins were also detected in the barley, wheat and maize raw ingredients. These metabolites are usually produced in the field during growth and remain after the field fungi have been replaced with storage fungi like Aspergillus and Penicillium. Sugar beet pulp, together with the extruded cereals and corn gluten seem to be the raw ingredients that are most susceptible to fungal contamination and thereby contribute the most to the overall mycotoxin content in the ready-to-eat feed.

The results of the chemical analyses show that 12 out of 25 ready-to-eat feed samples contained dihydro-demethyl-sterigmatocystin, a precursor to aflatoxin [34], possibly originating from contaminated maize gluten in the feed [35]. Eight of the ready-to-eat feed samples also contained enniatins. These metabolites together with deoxynivalenol are produced by Fusarium species in cereals $[21,36]$ and may originate from either corn gluten or the extruded barley or wheat ingredients. The fungal metabolites detected in the ready-to-eat feed products may not in themselves be able to cause negative health effects in mink, but the additive or synergistic effects of fungal metabolites together with high amounts of bacteria in the feed may explain syndromes like wasting mink disease. There are some studies on mink and mycotoxins (e.g. aflatoxin and ochratoxin), but no studies on other biologically active metabolites (e.g. enniatins). On the other hand, there are several examples of pets that have become seriously ill after eating mycotoxin-containing feed products. Canadian dogs, which ate moldy foods containing penitrems A and roquefortine have died [37] while other dogs vomited, and developed diarrhea and liver failure after having eaten molded cereal products [38]. Cats fed with T2 toxin, commonly found in moldy corn, contracted leukopenia (decreasing white blood cells), bloody stools and ataxia of the hind body [39]. However, the above studies did not take any "cocktail effects" of either bacteria/mycotoxin or mycotoxin/mycotoxin into consideration in the complexity of the problem.

Mycotoxins make up only a small part of the many biologically active metabolites molds can secrete into mink feed. Different metabolites have different biological activity depending on dose: few are acute toxic, some have an estrogen-like effect, others cause liver and kidney damage and others again are carcinogenic. A group of fungal metabolites are also able to suppress the immune system [40], which leads to a higher risk of bacterial and viral infections, which in turn results in increased miscarriage and higher antibiotics consumption. It is therefore necessary to prevent and control both bacterial and mold contamination in both raw materials and final ready-to-eat feed products.

\section{Conclusions}

Frequent microbiological control is important as many raw ingredients of mink feed have a very high number of bacteria and fungi and thus a short shelf life. The analytical methods have a natural limitation, as the sample volume is very small compared to the total production volume and microbial or chemical hotspots can easily be missed. As the raw material 
composition is constantly changing, potential cocktail effects should be considered when introducing new types of raw materials. Bacteria and fungi can spread to feed through contact with contaminated feed-handling equipment and grow in storage containers. Proper cleaning of equipment and proper timing of handling, storage, processing of ingredients and of the final products are essential to guarantee a high quality feed and to prevent or control infections in mink as well as the risk of exposure to humans from handling of mink feed. This study has shown that ready-to-eat mink feed can contain a cocktail of mycotoxins and bacteria, which may not in themselves cause clinical disease in the animals, but which may affect the overall health and well-being of the mink. These synergies may play an important role for the appearance of new disease complexes with unknown etiology.

\section{Supplementary information}

Supplementary information accompanies this paper at https://doi. org/10.1186/s13028-019-0489-6.

Additional file 1. Microbiological quality/bacterial counts in raw ingredients of animal origin and ready-to-eat feed at producer A in 2016.

Additional file 2. Microbiological quality/bacterial counts in raw ingredients of animal origin and ready-to-eat feed at producer B in 2016.

Additional file 3. Microbiological quality/bacterial counts in raw ingredients of animal origin and ready-to-eat feed at producer C in 2016.

Additional file 4. Microbiological quality/bacterial counts in raw ingredients of animal origin and ready-to-eat feed at producer A in 2017.

Additional file 5. Microbiological quality/bacterial counts in raw ingredients of animal origin and ready-to-eat feed at producer B in 2017.

Additional file 6. Microbiological quality/bacterial counts in raw ingredients of animal origin and ready-to-eat feed at feed producer C in 2017.

Additional file 7. Qualitative determination of mycotoxins and other biologically active metabolites present in samples of ready-to-eat feed from the three feed producers (A to C).

\section{Acknowledgements}

The authors would like to sincerely acknowledge the feed producers for their cooperation. We are grateful for the financial support from Dansk Pelsdyravlerforenings Forskningsfond. The authors wish to thank Anna Cecilie Boldt Eiersted, Annie Ravn Pedersen, Susanne M. Ranebro, Bojana Brinkmann Sörensen, Jannie Stjernholm, Lisette Knoth-Nielsen and Helle Ruby for their excellent technical assistance.

\section{Authors' contributions}

MC, UL and KP planned the study. MC performed the sampling. UL and $\mathrm{BN}$ did the bacteriology. BA and HF performed the fungal and mycotoxin analyses. $\mathrm{CH}$ did the detection of influenza virus $\mathrm{A}$. UL, BA, HF and $\mathrm{CH}$ drafted the manuscript with contributions from MC, BN and KP. All authors read and approved the final manuscript.

\section{Funding}

This project was supported by a Grant from Dansk Pelsdyravlerforenings Forskningsfond.

\section{Availability of data and materials}

The datasets during and/or analysed during the current study are available from the corresponding author on reasonable request.
Ethics approval and consent to participate

Not applicable.

\section{Consent for publication}

Not applicable.

\section{Competing interests}

The authors declare that they have no competing interests.

\section{Author details}

${ }^{1}$ National Veterinary Institute, Technical University of Denmark, Kemitorvet, Building 202, 2800 Kgs. Lyngby, Denmark. ${ }^{2}$ National Food Institute, Technical University of Denmark, Kemitorvet, Building 202, 2800 Kgs. Lyngby, Denmark. ${ }^{3}$ Department of Biotechnology and Biomedicine, Technical University of Denmark, Søltofts Plads, Building 221, 2800 Kgs. Lyngby, Denmark. ${ }^{4}$ Department of Animal Health and Antimicrobial Strategies, National Veterinary Institute, Ulls väg 2B, 75189 Uppsala, Sweden. ${ }^{5}$ Present Address: Institute for Molecular Medicine Finland (FIMM), University of Helsinki, P.O.Box 20, Tukholmankatu 8, 00014 Helsinki, Finland. ${ }^{6}$ Present Address: Statens Serum Institut, Artillerivej 5, 2300 Copenhagen S, Denmark. 7 Present Address: Environmental Protection Agency, Tolderlundvej 5, 5000 Odense C, Denmark.

Received: 30 January 2019 Accepted: 30 October 2019

Published online: 21 November 2019

\section{References}

1. Juokslahti T. Bacteriological quality of raw materials in Finnish mink feed. Acta Vet Scand. 1979;20:562-71.

2. Dietz HH, Chriél M, Andersen TH, Jørgensen JG, Torpdahl M, Pedersen H, et al. Outbreak of Salmonella Dublin-associated abortion in Danish fur farms. Can Vet J. 2006:47:1201-5.

3. Biström M, Moisander-Jylhä AM, Heinikainen S, Pelkola K, RaunioSaarnisto M. Isolation of Clostridium limosum from an outbreak of metritis in farmed mink. Acta Vet Scand. 2016. https://doi.org/10.1186/s1302 8-016-0230-7.

4. Hammer AS, Andresen L, Aalbæk B, Damborg P, Weiss V, Christiansen ML, et al. Abortion and mortality in farm mink (Neovison vison) associated with feed-borne Clostridium limosum. Vet Microbiol. 2017;203:229-33.

5. Hansen JE, Larsen AR, Skov RL, Chriél M, Larsen G, Angen $\varnothing$, et al. Livestock-associated methicillin-resistant Staphylococcus aureus is widespread in farmed mink (Neovison vison). Vet Microbiol. 2017;207:44-9.

6. Bursian SJ, Mitchell RR, Yamini B, Fitzgerald SD, Murphy PA, Fernandez G, et al. Efficacy of a commercial mycotoxin binder in alleviating effects of ochratoxin A, fumonisin B1, moniliformin and zearalenone in adult mink. Vet Hum Toxicol. 2004;46:122-9.

7. Bonna RJ, Aulerich RJ, Bursian SJ, Poppenga RH, Braselton WE, Watson GL. Efficacy of hydrated sodium calcium aluminosilicate and activated charcoal in reducing the toxicity of dietary aflatoxin to mink. Arch Environ Contam Toxicol. 1991;20:441-7.

8. Wu W, Zhou HR, Bursian SJ, Pan X, Link JE, Pestka JJ. Comparison of anorectic and emetic potencies of deoxynivalenol (vomitoxin) to the plant metabolite deoxynivalenol-3-glucoside and synthetic deoxynivalenol derivatives EN139528 and EN139544. Toxicol Sci. 2014. https://doi. org/10.1093/toxsci/kfu166.

9. Jensen VF, Sommer HM, Struve T, Clausen J, Criel M. Factors associated with usage of antimicrobials in commercial mink (Neovison vison) production in Denmark. Prev Vet Med. 2016;126:170-82.

10. Jensen VF, Sommer HM, Struve T, Clausen J, Criel M. A cross-sectional field study on potential associations between feed quality measures and usage of antimicrobials in commercial mink (Neovison vison). Prev Vet Med. 2017. https://doi.org/10.1016/j.prevetmed.2017.04.012.

11. Rattenborg E, Chriél M, Dietz HH. Influence of farm, feed-producer and season on incidence of gastrointestinal disorders in Danish farm mink. Prev Vet Med. 1999;38:231-7.

12. O'Brien TF. Emergence, spread, and environmental effect of antimicrobial resistance: how use of an antimicrobial anywhere can increase resistance to any antimicrobial anywhere else. In: Barza MD, Sherwood LG, editors. The need to improve antimicrobial use in agriculture: ecological and 
human health consequences. Chicago: The Chicago University Press; 2002. p. S78-S84.

13. Diarra MS, Delaquis $P$, Rempel H, Bach S, Harlton C, Aslam M, et al. Antibiotic resistance and diversity of Salmonella enterica serovars associated with broiler chickens. J Food Prot. 2014. https://doi.org/10.4315/0362028.JFP-13-251.

14. ISO 4833-2:2013. Microbiology of the food chain —horizontal method for the enumeration of microorganisms - part 2: colony count at $30^{\circ} \mathrm{C}$ by the surface plating technique.

15. ISO 21528-2:2004. Microbiology of the food chain - horizontal method for the detection and enumeration of Enterobacteriaceae-part 2: colonycount technique.

16. ISO 7937:2004. Microbiology of food and animal feeding stuffs-horizontal method for the enumeration of Clostridium perfringens-colony-count technique.

17. ISO 16649-2:2001. Microbiology of food and animal feeding stuffshorizontal method for the enumeration of beta-glucuronidase-positive Escherichia coli-part 2: colony-count technique at 44 degrees $C$ using 5-bromo-4-chloro-3-indolyl beta-D-glucuronide.

18. ISO 6888-1:1999. Microbiology of food and animal feeding stuffs-horizontal method for the enumeration of coagulase-positive staphylococci (Staphylococcus aureus and other species) - part 1: technique using Baird-Parker agar medium.

19. ISO 6579-1:2017 Microbiology of the food chain-Horizontal method for the detection, enumeration and serotyping of Salmonella - part 1: detection of Salmonella spp.

20. Maes N, Magdalena J, Rottiers S, De Gheldre Y, Struelens MJ. Evaluation of a triplex PCR assay to discriminate Staphylococcus aureus from coagulasenegative staphylococci and determine methicillin resistance from blood cultures. J Clin Microbiol. 2002;40:1514-7.

21. Samson RA, Houbraken J, Thrane U, Frisvad JC, Andersen B. Food and indoor fungi. CBS laboratory manual series 2. Utrecht: CBS-Fungal Biodiversity Centre; 2010.

22. Trebbien R, Bragstad K, Larsen LE, Nielsen J, Bøtner A, Heegaard PMH, et al. Genetic and biological characterisation of an avian-like H1N2 swine influenza virus generated by reassortment of circulating avian-like H1N1 and H3N2 subtypes in Denmark. Virol J. 2013;10:290-306.

23. Doyle MP, Buchanan RL. Food microbiology: fundamentals and frontiers. 4th ed. Washington DC: ASM Press; 2013.

24. Lindgren S. Storage of waste products for animal feed. In: Wood BJB, editor. The lactic acid bacteria, vol. 1. Boston: Springer; 1992.

25. Wlazło Ł, Nowakowicz-Dębek B, Fiołka M, Krukowski H, Zoń A, Trawińska B, Bryl M. The effect of sodium bentonite supplementation in the diet of mink (Neovison Vison) on the microbiological quality of feed and animal health parameters. Slov Vet Res. 2015;52:165-71.

26. Hildebrandt H. Bacterial diseases of mink. In: Merck veterinary manual. 2015. https://www.merckvetmanual.com/exotic-and-laboratory-animals/ mink/bacterial-diseases-of-mink. Accessed 30th Jan 2029.
27. Larsen LE, Breum SØ, Trebbien R, Bradstad K, Nielsen LP, Chriél M, et al Outbreaks of influenza A virus in farmed mink (Neovison vison) in Denmark: molecular characterization of the viruses. In: Proc. Xth Int. Scientific Congr. in Fur Animal Production: Scientifur 2012;36(3/4):153-6.

28. Gagnon CA, Spearman G, Hamel A, Godson DL, Fortin A, Fontaine G, et al. Characterization of a Canadian mink H3N2 influenza A virus isolate genetically related to triple reassortant swine influenza virus. J Clin Microbiol. 2009;47:796-9.

29. Hansen J. Methicillin-resistant Staphylococcus aureus in Danish production animals. Ph.D thesis, Technical University of Denmark, National Veterinary Institute, Lyngby; 2018.

30. Labuda R, Tancinova D. Fungi recovered from Slovakian poultry feed mixtures and their toxinogenity. Ann Agric Environ Med. 2006;13:193-200.

31. Domsch KH, Gams W, Anderson TH. Compendium of soil fungi. 2nd taxonomy revised ed. In: Gams W, editor. Eching: IHW; 2007.

32. Pitt Jl, Hocking AD. Fungi and food spoilage. Boston: Springer; 2009. p. $1-519$.

33. Frisvad JC, Andersen B, Thrane U. The use of secondary metabolite profiling in chemotaxonomy of filamentous fungi. Mycol Res. 2008;1 12:231-40.

34. Yu J, Woloshuk CP, Bhatnagar D, Cleveland TE. Cloning and characterization of avfA and omtB genes involved in aflatoxin biosynthesis in three Aspergillus species. Gene. 2000;248:157-67.

35. Battilani P, Costa LG, Dossena A, Gullino M. L, Marchelli R, Galaverna G, et al. Scientific information on mycotoxins and natural plant toxicants. EFSA Supporting Publications. 2009;6(9). https://doi.org/10.2903/ sp.efsa.2009.en-24.

36. Prosperini A, Berrada H, Ruiz MJ, Caloni F, Coccini T, Spicer LJ, et al. A review of the mycotoxin enniatin B. Front Public Health. 2017. https://doi. org/10.3389/fpubh.2017.00304

37. Naude TW, O'Brien OM, Rundberget T, McGregor ADG, Roux C, Flaoyen A. Tremorgenic neuromycotoxicosis in 2 dogs ascribed to the ingestion of penitrem A and possibly roquefortine in rice contaminated with Penicillium crustosum: clinical communication. J S Afr Vet Assoc. 2002;73:211-5.

38. Puschner B. Mycotoxins. Vet Clin N Am Small Anim Pract. 2002;32:409-19.

39. Lutsky II, Mor N. Alimentary toxic aleukia (septic angina, endemic panmyelotoxicosis, alimentary hemorrhagic aleukia): $t-2$ toxin-induced intoxication of cats. Am J Pathol. 1981;104:189-91.

40. Ghareeb K, Awad WA, Böhm J, Zebeli Q. Impacts of the feed contaminant deoxynivalenol on the intestine of monogastric animals: poultry and swine. J Appl Toxicol. 2015;35:327-37.

\section{Publisher's Note}

Springer Nature remains neutral with regard to jurisdictional claims in published maps and institutional affiliations.
Ready to submit your research? Choose BMC and benefit from:

- fast, convenient online submission

- thorough peer review by experienced researchers in your field

- rapid publication on acceptance

- support for research data, including large and complex data types

- gold Open Access which fosters wider collaboration and increased citations

- maximum visibility for your research: over 100M website views per year

At BMC, research is always in progress.

Learn more biomedcentral.com/submissions 